
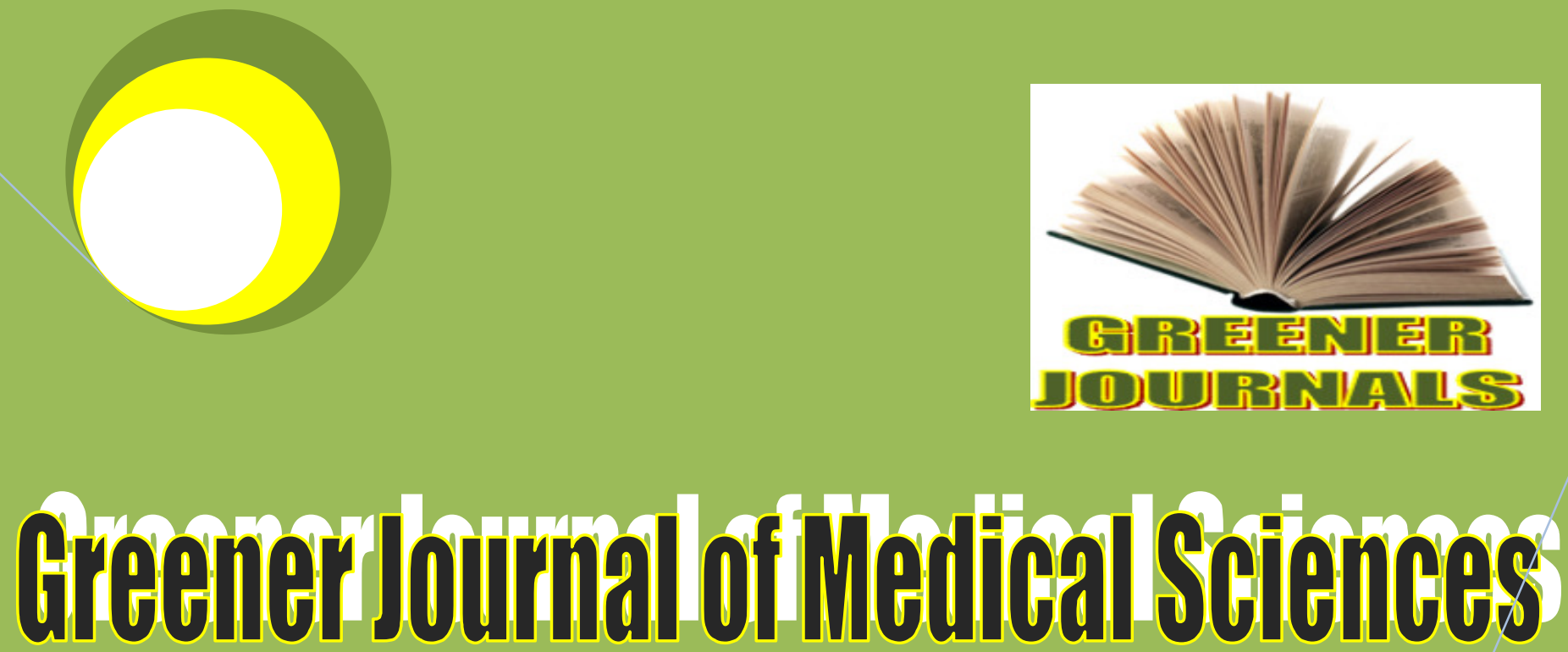

ISSN: 2276-7797 Impact Factor 2012 (UJRI): 0.7634 ICV 2012: 5.98

Significance of maternal antenatal health care intervention in reducing the occurrence of neonatal low birthweight especially in mothers of low socioeconomic class? Data from Jere community of Borno state, Nigeria

By

Baba Usman Ahmadu Machoko Yenti Akuhwa Randolph Tartenger Takwale Joseph Aliyu Bappa Aisha 


\title{
Significance of maternal antenatal health care intervention in reducing the occurrence of neonatal low birthweight especially in mothers of low socioeconomic class? Data from Jere community of Borno state, Nigeria
}

\author{
${ }^{1 *}$ Baba Usman Ahmadu, ${ }^{2}$ Machoko Yenti, ${ }^{3}$ Akuhwa Randolph \\ Tartenger, ${ }^{4}$ Takwale Joseph, ${ }^{5}$ Aliyu Bappa Aisha \\ ${ }^{1,4,5}$ Department of Paediatrics, Federal Medical Centre, Yola, Adamawa state, Nigeria. \\ ${ }^{2,3}$ Department of Paediatrics, University of Maiduguri Teaching Hospital, Maiduguri, Nigeria. \\ ${ }^{1 *}$ Corresponding Author: Email: ahmadu4u2003@yahoo.com, Tel: +2348033668948
}

\begin{abstract}
Background: low birthweight is associated with increased childhood morbidity and mortality particularly in Nigeria where poverty levels are also high, and most individuals are found in low socioeconomic class. There is now growing evidence that low birth weight could be reduced through access to good maternal antenatal health care. This review deals with the role of maternal antenatal health care delivery in lowering neonatal birthweight, especially in mothers who belong to low socioeconomic class.

Methods: One hundred and sixty six mother-neonatal pairs were selected using systematic random sampling method. Maternal socioeconomic class was estimated using oyedeji scoring model and neonatal birthweight was determined using bassinet weighing scale.

Results: All mothers $166(100 \%)$ had antenatal care. Out of 166 neonates in this study, $84(50.6 \%)$ neonates were males and $105(63.3 \%)$ had normal birthweight. Sixty-nine (41.6\%) mothers had primary education, $81(48.8 \%)$ were unemployed and $111(66.9)$ had low socioeconomic class. Nineteen neonates (11.4\%) had low birthweight and mean birthweight of neonates whose mothers belong to low socioeconomic class was slightly lower than those of high socioeconomic class. This was however not significant $(p=0.459)$. Association between maternal socioeconomic class and neonatal birthweight was also not significant $(p=0.565)$.

Conclusion: Maternal antenatal health care services are crucial for reduction in number of low birthweight in neonates across maternal socioeconomic classes.
\end{abstract}

Keywords: Mother-neonatal pairs, Antenatal care, Birthweight, Socioeconomic class.

\section{INTRODUCTION}

Worldwide incidence of low birthweight (LBW) has been reported as 17\% per annum, making LBW an important infant health problem globally (Torres-Arreola et al., 2005). The incidence of LBW varies among populations, between $4 \%$ and $6 \%$ in populations of developed countries and much higher in those of developing countries (Torres-Arreola et al., 2005). The Paediatric Annual conference of Nigeria has estimated that the LBW rate for Nigeria is 14\% (Okolo, 2009), whereas the Pan American Health Organization has estimated 6\% for Peru and $10 \%$ for Bolivia (Castillo-Salgado, 2000). In 2002, Jefferis et al. (2002) in London have identified a link between LBW with increased incidence of neurological deficits or poorer cognitive skills in childhood compared with counterparts having normal birthweight. More recent, in mexico, Torres-Arreola et al (2005) have added that, LBW could be associated with heighten risk of infection, malnutrition and handicapping conditions among others.

The biological processes that affect the fetus in-utero are related to the mother's physiology, including her nutrition, exercise, infections, consumption of tobacco, alcohol and other drugs (Lynch and Kaplan, 2000; Kramer, 
1987). During the fetal phase, growth depends on the nutritional condition of the mother, indicating that pregnant women should not only increase their weight but also consume essential nutrients. For many women in the developing world, however, social and economic factors make it difficult for them to obtain the necessary food and healthcare, which are closely interrelated (UNICEF, 2003). Studies conducted mainly in advanced societies have shown that antenatal care services (ANC), and other maternal health care interventions have reduced immensely the risk of LBW deliveries (Michael, 1995). Nigeria is a country with a population density of 142 people per square kilometer and most of these people are living below the poverty line, however, adult literacy rate is put at $66.8 \%$ (WHO, 2006).

Relationship between antenatal health care intervention and the possible reduction in the occurrence of neonatal LBW especially in mothers of low socioeconomic class (SEC) have been of interest to many investigators. In two publications, Marmot et al. (1996) and Wadsworth (1999) considered health as an important determinant of opportunities in life via a process called selection by health (Marmot and Shipley, 1996; Wadsworth, 1999). They suggested that health selects people in different social strata of life. Yet dearth of data on ANC health intervention in lowering neonatal LBW occurrences still exists in this part of the world. Thus, the major objectives of this present study were two fold:

1) To provide scientific data on the contributory role of maternal ANC delivery in lowering neonatal birthweight outcome.

2) To provide information that would have public health significance and relevance to policy development and program implementation, as it relates to the overall maternal and fetal wellbeing in Nigeria and other developing nations.

\section{MATERIALS AND METHODS}

\section{Study Area}

The study was carried out at the Department of Paediatrics and Obstetrics unit of the University of Maiduguri Teaching Hospital (UMTH), Nigeria. The UMTH is a tertiary centre located in North-Eastern Nigeria and a centre of excellence for infectious diseases and immunology. Apart from being the largest health facility in the area, UMTH serves as a referral centre for the six North-Eastern States and neighboring countries of Chad, Cameroon and Niger Republics.

\section{Ethical Considerations}

The study protocol was reviewed and authorised by the Medical Research and Ethics Committee of the UMTH. The approval was on the agreement that patient anonymity must be maintained, best clinical practice be ensured, and that every finding would be treated with utmost confidentiality and for the purpose of this research only. All work was performed according to the international guidelines for human experimentation in clinical research (World Medical Association Declaration of Helsinki, 2000).

\section{Sampling Technique/Study Population}

The minimum sample size was determined using statistical formula that computes $10 \%$ prevalence for LBW at 95 confidence interval and alpha levels of 0.05 (Torres-Arreola et al., 2005; Naing et al., 2006). This equalled 138; however, $20 \%$ of this was added to maximize power. Therefore, the study population comprised of 166 motherneonatal pairs. A pregnant woman was eligible for participation in the study if she delivered at labour ward of UMTH and met the following study inclusion criteria:

(i) did ANC and had an uncomplicated singleton birth at term (based on fundal height or Obstetric ultrasound scan or Eregie $^{15}$ estimate of gestational age),

(ii) Had no known underlying chronic illness and not on drugs other than the ones used for routine ANC.

Mothers who smoke cigarette and drink alcoholic beverages or coffee were also excluded from this study. Motherneonatal pairs were enrolled in this study using the systematic random sampling method where the first of every three mother-neonatal pairs were picked at the labour ward. Where the first mother-neonatal pair did not fulfil the inclusion criteria above, the immediate next mother-neonatal pair that qualified was selected. 
Following informed consent, at delivery, information was obtained on the delivery outcome including baby's sex, and birth weight $(\mathrm{kg})$. The birth weight was determined using the bassinet weighing scale immediately after childbirth. Neonates weighing $<2.5(\mathrm{~kg})$ were considered LBW, those weighing $>3.99$ kilograms $(\mathrm{kg})$ were classified as macrosomia and those weighing between $2.5-3.99(\mathrm{~kg})$ as normal, similar to other publications elsewhere (Torres-Arreola et al., 2005; Uche, 2007). Demographic, antenatal care and SEC indicators of the participants were obtained from case files of each individual and by interview.

\section{Maternal socioeconomic class scoring model}

Maternal SEC was assessed based on their occupation and educational attainment using the Oyedeji scoring model (Oyedeji, 1985). Maternal SEC that is Class I-III was considered as high SEC, with class I higher than class II and class II higher than class III. Class IV-V was considered to be low SEC with class V being lower than class IV. Each mother-neonatal pair was allotted a serial number at birth.

\section{Statistical Analysis}

The data obtained from the study were entered into a computer for statistical analysis using statistical package for social science (SPSS) statistical software version 16, Illinois, Chicago USA. Values were expressed as percentages, means and standard deviations (SD). Differences in means were evaluated using Student $t$ test and analysis of variance ANOVA, while differences between proportions were evaluated using Chi-square $\left(X^{2}\right)$ tests. Statistical significance were achieved at $\mathrm{P}<0.05$. Tables were used for illustrations.

\section{RESULTS}

Table 1 below shows birth profile and the sociodemographic characteristics of mother-neonatal pairs. Of the 166 neonates $84(50.6 \%)$ were males, and $105(63.3 \%)$ had normal birthweight. All mothers had ANC health intervention. Sixty-nine of them 69 (41.6\%) had primary education, 81 (48.8\%) were unemployed and 111 (66.9) had low SEC.

Nineteen neonates (11.4\%) had LBW and the overall mean neonatal birth weight was $3.05 \pm 0.58(95 \% \mathrm{Cl}$, $2.96-3.13)$. Although the mean birth weight of neonates whose mothers belong to low SEC was lower than those of high SEC mothers (table 2), this was however not significant $(p=0.459)$.

Table 3 revealed the relationship between maternal education, occupation and mean neonatal birthweight. Comparing mean neonatal birthweight according to the different classes of maternal education and occupation were insignificant $(p=0.594)$ for maternal education, and $(p=0.417)$ for maternal occupation.

Table 4 shows the distribution of maternal SEC and birthweight of the neonates. Association between maternal SEC and birthweight of the neonates was not significant $(p=0.565)$. 
Table 1: Birth profile and Socio-demographic characteristics of mother-neonatal pairs

\begin{tabular}{|c|c|c|}
\hline Parameters & Frequency & Percentage (\%) \\
\hline $\begin{array}{l}\text { Sex of neonates } \\
\text { Male }\end{array}$ & 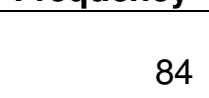 & 50.6 \\
\hline Female & 82 & 49.4 \\
\hline $\begin{array}{l}\text { Neonatal birthweight } \\
\text { Low birthweight }\end{array}$ & 19 & 11.4 \\
\hline Normal birthweight & 105 & 63.3 \\
\hline Macrosomia & 42 & 25.3 \\
\hline Maternal education & & \\
\hline Class I: University graduate or equivalent & 12 & 7.2 \\
\hline Class II: School certificate (GCE/SSCE) holders & 20 & 12.1 \\
\hline $\begin{array}{l}\text { Class III: School certificate or grade II teachers' certificate } \\
\text { holders }\end{array}$ & 52 & 31.3 \\
\hline Class IV: Those with primary six certificates & 69 & 41.6 \\
\hline $\begin{array}{l}\text { Class V: Those who could just either read and write or } \\
\text { illiterate }\end{array}$ & 13 & 7.8 \\
\hline $\begin{array}{l}\text { Maternal occupation } \\
\text { Class I: Senior public servants, professionals, large-scale } \\
\text { businessmen }\end{array}$ & 5 & 3.0 \\
\hline $\begin{array}{l}\text { Class II: Intermediate grade public servants, and senior } \\
\text { school teachers. }\end{array}$ & 7 & 4.2 \\
\hline Class III: Junior school teachers, drivers and artisans. & 13 & 7.8 \\
\hline $\begin{array}{l}\text { Class IV: Petty traders, labourers, messengers and similar } \\
\text { grades. }\end{array}$ & 60 & 36.2 \\
\hline $\begin{array}{l}\text { Class V: Unemployed, full housewives, students, } \\
\text { subsistence farmers. }\end{array}$ & 81 & 48.8 \\
\hline $\begin{array}{l}\text { Maternal socioeconomic class } \\
\text { High }\end{array}$ & 55 & 33.1 \\
\hline Low & 111 & 66.9 \\
\hline
\end{tabular}


Table 2: Maternal socioeconomic class and neonatal birthweight of the study group

\begin{tabular}{|l|c|c|c|}
\hline Maternal SEC & \multicolumn{3}{|c|}{ Birthweight of the neonates (kg) } \\
& \multicolumn{2}{|c|}{ Mean (SD) } & $95 \%$ Cl \\
\hline High & $3.20(0.62)$ & $3.03-3.37$ \\
Low & $3.12(0.67)$ & $2.99-3.24$ \\
p value ${ }^{a}$ & 0.459 & - \\
\hline
\end{tabular}

Table 3: Relationship between maternal education, occupation and mean neonatal birthweight

\begin{tabular}{|c|c|c|}
\hline \multirow[t]{2}{*}{ Maternal variables } & \multicolumn{2}{|c|}{ Neonatal birthweights $(\mathrm{kg})$} \\
\hline & Mean (SD) & $95 \% \mathrm{Cl}$ \\
\hline Education & & \\
\hline Class I: University graduate or equivalent & $3.08(0.67)$ & 2.66-3.51 \\
\hline Class II: School certificate (GCE/SSCE) holders & $2.90(0.97)$ & 2.45-3.35 \\
\hline Class III: School certificate or grade II teachers' certificate & $3.17(0.62)$ & 3.00-3.35 \\
\hline Class IV: Those with primary six certificates & $3.17(0.57)$ & 3.04-3.31 \\
\hline Class V: Those who could just either read and write or & $3.08(0.95)$ & $2.50-3.65$ \\
\hline$p=$ value $^{b}$ & 0.594 & - \\
\hline $\begin{array}{l}\text { Maternal occupation } \\
\text { Class I: Senior public servants, professionals, large-scale } \\
\text { businessmen }\end{array}$ & $3.00(0.71)$ & $2.12-2.88$ \\
\hline $\begin{array}{l}\text { Class II: Intermediate grade public servants, and senior } \\
\text { school teachers. }\end{array}$ & $3.14(0.69)$ & $2.50-3.78$ \\
\hline Class III: Junior school teachers, drivers and artisans. & $3.46(0.52)$ & 3.15-3.78 \\
\hline $\begin{array}{l}\text { Class IV: Petty traders, labourers, messengers and similar } \\
\text { grades. }\end{array}$ & $3.07(0.71)$ & 2.88-3.25 \\
\hline $\begin{array}{l}\text { Class V: Unemployed, full-time housewives, students and } \\
\text { subsistence farmers. }\end{array}$ & $3.15(0.64)$ & $3.01-3.29$ \\
\hline$p=$ value $^{b}$ & 0.417 & - \\
\hline
\end{tabular}


Table 4: Association between maternal socioeconomic class and birthweight of the neonates

\begin{tabular}{|c|c|c|c|c|}
\hline \multirow[t]{2}{*}{ Maternal SEC } & \multicolumn{3}{|c|}{ Neonatal birthweight (kg) (\%) } & \multirow[t]{2}{*}{ Total } \\
\hline & LBW $(<2.5)$ & NBW (2.5-3.99) & Macrosomia ( $\geq 4.0$ ) & \\
\hline High & $6(3.6)$ & $33(19.9)$ & $17(10.2)$ & $56(33.7)$ \\
\hline Low & $13(7.8)$ & $72(43.4)$ & $25(15.1)$ & $110(66.3)$ \\
\hline Total & $19(11.4)$ & $105(63.3)$ & $42(25.3)$ & $166(100)$ \\
\hline
\end{tabular}

$S E C=$ Socioeconomic class $L B W=$ Low birth weight $N B W=$ Normal birth weight

\section{DISCUSSION}

Maternal SEC has been reported to influence reproductive performance of mothers and neonatal birth weight outcome. In this light, low maternal SEC would result to LBW in neonates and vice-versa. However, if mothers were given ANC, there could be a reduction in the number of neonates that are born with LBW. Our study revealed that $11.4 \%$ of the neonates had LBW and maternal social variables (education and occupation) did not contribute to this. This is consistent with the observation made by another abroad (Michael, 1995). Possible reason for this could be that these maternal social variables are likely to be artifacts based on certain instinct, and may not give reliable results despite the existence of social inequalities in a given population. Colleagues elsewhere have pointed out that low ranking of maternal education and occupation among other social indices are less likely to yield neonates with LBW, if each of these definitions are held constant (Michael, 1995). The reason for this is not fully understood (Torres-Arreola et al., 2005).

However, some researchers argued that Low maternal SEC may lead to LBW based on social selection. Social selection holds that people who are ill or capable of becoming sick are assumed to be from low social status, while healthy people are from high social strata (Michael, 1995; Stern, 1983). Because of lack of enough evidence, social selection remains rather a hypothesis than a proved fact (Townsend et al., 1988). Moreover, all humans have the tendencies to be sick irrespective of social ranking as such, social selection may not hold true in all circumstances. Still, many other investigators are of the view that low maternal social parameters early in life may have tremendous impact on the behaviours of prospective mothers as an adult (Spencer and Logan, 2002). Some of these behaviors, which can lead to LBW in neonates of prospective mothers, are cigarette smoking and alcoholism. For instance a woman whose parents were disadvantaged is more likely to have been low birth weight herself, to have experienced more childhood ill health with adverse effect on her growth (Michael, 1995; Spencer and Logan, 2002). She is most likely to indulge in alcoholism and smoking as an adolescence and more likely to be pregnant and give birth to neonates with LBW (Spencer and Logan 2002).

Of significance was the use of two social indicators to construct our SEC model in order to reduce the possible error of misclassifying our subjects. That was done by combining maternal education and occupation, which is similar to a previously published study (Torres-Arreola et al., 2005). Low maternal SEC in current study has no significant impact on LBW and in general, association between maternal SEC and neonatal birthweight outcome was not significant. This conformed to a finding of a study, in which household infrastructure that included poor sanitation or water facilities and electricity when used as low SEC indicators (Hughes and Simpson, 1995). However, other workers have observed that less or no ownership of goods and not being gainfully employed resulted to LBW in neonates (Torres-Arreola et al., 2005). Differences observed in all these results about the effect of maternal SEC on LBW are probably due to the use of various maternal SEC indicators. Of emphasis, however, is that obtaining accurate information which will reflect maternal social and economic characteristics can be difficult. On the basis of this, proxy variable were generated for use in this study. Thus, maternal education and occupation have been used as proxies for social class, and the duo combination was used as proxy for SEC in present study. This methodology was in agreement with the ones used by many other researchers (Torres-Arreola et al., 2005; Lynch and Kaplan, 2000; Kramer, 1987; Nordstrom and Cnattingius, 1996). 
Most importantly, all mothers in this study had health intervention by way of ANC services during pregnancy. This could be the reason why the proportion of neonates with LBW was the least. To add, this could also explain the lack of association between low maternal SEC and LBW in our neonates. Even though slight insignificant decreased in mean birthweight was noticed in neonates of low SEC mothers compared to those of high SEC mothers. Numerous workers have demonstrated that SEC has an effect on health outcomes because mothers at the bottom of the SEC scale suffer from deprivation, and are part of a culture in which the predominant forms of health behaviors are considered harmful (Michael, 1995). Maternal deprivation would mean lack of quality access to health care services among others, which puts the foetus at risk of starting out with LBW.

Our inability to assess other possible factors such as maternal anthropometry, nutrition and parity which may contribute to LBW in neonates in the present study population was a drawback to this investigation and remains a limitation of this study. These limitations may have affected the adequate assessment of the contributory role of maternal ANC health intervention in lowering LBW occurrences in our neonates. Future research incorporating these aspects is advocated.

\section{CONCLUSION}

Although many socioeconomic factors related to LBW have been identified, the specific role of each of them is not known, limiting the ability to use preventive actions in exposed populations. This has made health interventions aimed at reducing the number of LBW in neonates of limited success in the past nonetheless; however, some of this health intervention are of benefits now in pregnant women. To decrease the incidence of LBW in neonates, it is important to consider ANC health services in order to give quality health care for pregnant women. Health care investments in a population, most especially that of pregnant women and children is important in order for a society to achieve high human development index.

\section{Competing interests}

The authors declare that they have no competing interests.

\section{Funding source}

Authors of this work funded the study.

\section{Authors' contributions}

BUA conceived and designed the study, BUA, MY, and ART assessed and interpreted the data. All authors are involved in critical revision of the paper, writing draft report and final approval of the manuscript.

\section{Acknowledgements}

We acknowledge the kind help and encouragement we received from the midwives, medical and administrative staff of the UMTH.

\section{REFERENCES}

Torres-Arreola LP, Constantino-Casas P, Flores-Hernández S, Villa-Barragán JP, Rendón-Macías E (2005). Socioeconomic factors and low birth weight in Mexico. BMC Public Health. 5:20 -7.

Okolo A (2009). Overview of Neonatal Mortality - Global Perspectives. PANCONF. S1-S43.

Castillo-Salgado C (2000). Health situation analysis in the Americas, 1999-2000. Special Program for Health Analysis. Regional Core Health Information System. Epidemiological Bulletin/PAHO . 21(4):S1-S16.

Jefferis BJM, Chris Power C, Hertzman C (2002). Birth weight, childhood socioeconomic environment, and cognitive development in the 1958 British birth cohort study. BMJ. 325:305-11.

Lynch J, Kaplan G (2000). Socioeconomic Position. In: Berkman LF, Kawachi I, editors. Social epidemiology Oxford University Press. p.13-35.

Kramer MS (1987). Determinants of low birth weight: Methodological assessment and meta-analysis. Bull Wld Hlth Org. 65:663-737. 
Estado Mundial de la Infancia, UNICEF (2003). [http://www.unicef.org/spanish/pubsgen/sowc03/sowc03-sp.pdf]. January $15^{\text {th }} 2004$.

Michael DK (1995). Social causes of low birth weight. J R Soc Med. 88:611-15.

World Health Organisation (2006). Country health system fact sheet Nigeria.

Antonovsky A (1967). Social class, life expectancy and overall mortality. Milbank Memorial Fund Quarterly. 45:31-73.

Marmot MG, Shipley MJ (1996). Do socioeconomic differences in mortality persist after retirement? 25 year follow up of civil servants from the first Whitehall study. BMJ. 313:1177-80.

Wadsworth M (1999). Early life. In: Michael M, Richard G W, Editors. Social determinants of health. Oxford University Press. Oxford;:44-52.

World Medical Association Declaration of Helsinki (2000). Ethical principles for medical research involving human subjects. World Medical Association, 2000. Available at http://www.wma.net/e/policy/b3.htm. Accessed June 15, 2005.

Naing L, Winn T, Rusli BN (2006). Practical Issues in Calculating the Sample Size for Prevalence Studies. Archives of Orofacial Sciences. 1: 9-14.

Eregie CO (1991). Gestational age and maturity score. J Trop Paediatr. 37:184-197.

Uche N (2007). Assessment and care of the newborn. In: Azubuike JC, Nkanginieme K

EO, editorss. Paediatrics and Child Health in a Tropical Region. $2^{\text {nd }}$ ed. Owerri: African Educational Services. p. 163177.

Oyedeji GA (1985). Socio-economic and cultural background of hospitalised children in Illesha. Nig J Paediatr. 12: $111-17$.

Stern J (1983). Social mobility and the interpretation of social class mortality differentials. JK Social Policy. 12:27-49.

Townsend P, Davidson N, Whitehead M (1988). Editors: Inequalities in Health (the Black Report and the Health Divide). London: Penguin Books.

Spencer N, Logan S (2002). Social influences on birth weight. Arch Dis Child Fetal Neonatal Ed. 86:6-7.

Hughes D, Simpson L (1995). The role of social change in preventing low birth weight. Future Child. 5:87-102.

Nordstrom ML, Cnattingius S (1996). Effects on birthweights of maternal education, socioeconomic status, and workrelated characteristics. Scandinavian Journal of Social Medicine. 24:55-61. 